\title{
Risk factors for revision surgery following primary adult spinal deformity surgery in patients 65 years and older
}

\author{
Varun Puvanesarajah, MD, ${ }^{2}$ Francis H. Shen, MD, ${ }^{1}$ Jourdan M. Cancienne, MD, ${ }^{1}$ \\ Wendy M. Novicoff, PhD, ${ }^{1}$ Amit Jain, MD, ${ }^{2}$ Adam L. Shimer, MD, ${ }^{1}$ and Hamid Hassanzadeh, MD' \\ 'Department of Orthopaedic Surgery, University of Virginia, Charlottesville, Virginia; and 2Department of Orthopaedic Surgery, \\ Johns Hopkins Hospital, Baltimore, Maryland
}

\begin{abstract}
OBJECTIVE Surgical correction of adult spinal deformity (ASD) is a complex undertaking with high revision rates. The elderly population is poorly studied with regard to revision surgery, yet senior citizens constitute a rapidly expanding surgical demographic. Previous studies aimed at elucidating appropriate risk factors for revision surgery have been limited by small cohort sizes. The purpose of this study was to assess factors that modify the risk of revision surgery in elderly patients with ASD.
\end{abstract}

METHODS The PearlDiver database (2005-2012) was used to determine revision rates in elderly ASD patients treated with a primary thoracolumbar posterolateral fusion of 8 or more levels. Analyzed risk factors included demographics, comorbid conditions, and surgical factors. Significant univariate predictors were further analyzed with multivariate analysis. The causes of revision at each year of follow-up were determined.

RESULTS A total of 2293 patients who had been treated with posterolateral fusion of 8 or more levels were identified. At the 1-year follow-up, 241 (10.5\%) patients had been treated with revision surgery, while 424 (18.5\%) had revision surgery within 5 years. On univariate analysis, obesity was found to be a significant predictor of revision surgery at 1 year, while bone morphogenetic protein (BMP) use was found to significantly decrease revision surgery at 4 and 5 years of followup. Diabetes mellitus, osteoporosis, and smoking history were all significant univariate predictors of increased revision risk at multiple years of follow-up. Multivariate analysis at 5 years of follow-up revealed that osteoporosis (OR 1.98, 95\% $\mathrm{Cl} 1.60-2.46, \mathrm{p}<0.0001)$ and BMP use (OR 0.70,95\% $\mathrm{Cl} 0.56-0.88, \mathrm{p}=0.002)$ were significantly associated with an increased and decreased revision risk, respectively. Smoking history trended toward significance $(\mathrm{OR} 1.37,95 \% \mathrm{Cl}$ $1.10-1.70, p=0.005)$. Instrument failure was consistently the most commonly cited reason for revision. Five years following surgery, it was estimated that the cohort had $68.8 \%$ survivorship.

CONCLUSIONS For elderly patients with ASD, osteoporosis increases the risk of revision surgery, while BMP use decreases the risk. Other comorbidities were not found to be significant predictors of long-term revision rates. It is expected that within 5 years following the index procedure, over $30 \%$ of patients will require revision surgery.

http://thejns.org/doi/abs/10.3171/2016.2.SPINE151345

KEY WORDS adult spinal deformity; elderly; revision; spine fusion; posterolateral

$\mathrm{S}$ URGICAL correction of adult spinal deformity (ASD) is a complex undertaking that ranks among the most morbid of orthopedic procedures. The challenges that arise from surgical management of this pathology have resulted in high complication rates, ${ }^{3,4,34-36}$ particularly in elderly patients. ${ }^{9}$ Specifically, revision rates often range from $8 \%-45 \%$ following primary spine fusion procedures, increasing with greater follow-up. ${ }^{23,27,32,38}$ The elderly population is of particular interest given the rapidly rising need for care for this population; with improving healthcare and life expectancy, larger numbers of elderly patients are considering surgical spine treatment. ${ }^{11}$ Revision surgery in this patient population can pose a difficult problem, requiring physicians to weigh the pros and cons to determine an adequate solution. In patients with $\mathrm{ASD}$, revisions are often due to pseudarthrosis, $, 814,20-22,27,32,33$ implant failure, ${ }^{27,38}$ adjacent segment disease, ${ }^{8,15,22,27,33,38}$ or infection, ${ }^{22,24,27,32,38}$ resulting in increased healthcare costs

ABBREVIATIONS ASD = adult spinal deformity; $\mathrm{BMI}=$ body mass index; $\mathrm{BMP}=$ bone morphogenetic protein $; \mathrm{COPD}=$ chronic obstructive pulmonary disease; $\mathrm{CPT}=$ current procedural terminology; ICD-9 = International Classification of Diseases, 9th Revision.

SUBMITTED November 13, 2015. ACCEPTED February 8, 2016.

INCLUDE WHEN CITING Published online May 6, 2016; DOI: 10.3171/2016.2.SPINE151345. 
and procedural morbidity. These issues highlight the need for identifying revision risk factors in order to influence clinical decision-making and improve patient education.

Previous studies aimed at investigating predictive risk factors for reoperation following spine surgery have mostly focused on procedures for lumbar stenosis. ${ }^{5,10,12}$ Unfortunately, there are few studies $s^{25,27,38}$ that have investigated predictive risk factors for revision surgery following an index procedure for patients with ASD, with none focusing primarily on an elderly population, likely because of low cohort sizes at individual institutions.

The primary aim of this study is 2-fold: to characterize reoperation rates in elderly patients treated with 8-level or greater posterior fusion procedures for deformity and to assess the relative contribution of specific patient and surgery characteristics in determining the risk of eventual reoperation.

\section{Methods}

Data for the current study were acquired from the PearlDiver Patient Records Database (PearlDiver Inc.), which is a for-fee database. Data were acquired from the database using International Classification of Diseases, 9th Revision (ICD-9), diagnosis and procedure codes or current procedural terminology (CPT) codes. In total, procedural volumes, demographic information, and specific diagnoses can be accessed from over 40 million individual patient records from 2005 to 2012. Access to the database was granted by PearlDiver Technologies for the purpose of academic research. The database was stored on a password-protected server maintained by PearlDiver.

Patients with ASD who had been treated with a posterolateral fusion of 8 or more levels were considered for this study. Specifically, ICD-9 procedure codes for thoracolumbar and lumbosacral posterior fusions $(81.05,81.07$, and 81.08) were queried. The resultant group of patients was narrowed to include only those who were also coded as having undergone a fusion of 8 levels or greater (81.64). Fusions extending to the cervical spine were excluded $(81.01,81.02,81.03)$. Other exclusion criteria included any diagnoses of traumatic spine fracture, bone metastasis, primary bone cancer, or spine infection either on the day of surgery or prior to surgery (Appendix Table 1) and shoulder, knee, or hip replacement at any point following the index procedure. The latter exclusion criteria were used to avoid general revision surgery coding for revision procedures associated with other common surgical procedures. Patients who had undergone a revision fusion procedure were excluded as well. ICD-9 procedure codes for revision surgery are detailed in Table 1 . Lastly, only patients 65-84 years of age were selected, specifically those with a diagnosis of kyphosis or scoliosis on the same day as their index procedure. This resulted in a total of 2293 patients who were included for subsequent analysis.

Following a basic demographic assessment of the cohort, queries were attempted for the number of reoperations or revision spine surgeries after the index procedure at $1,2,3,4$, and 5 years of follow-up. The full cohort was then dichotomized based on several potential predictor variables. Demographic predictor variables included pa- tient age (dichotomized by a cutoff of 75 years) and sex. Comorbidities included diabetes mellitus, chronic obstructive pulmonary disease (COPD), peripheral vascular disease, obesity, smoking history, and osteoporosis. Surgical and postsurgical factors that were assessed included transfusion on the day of surgery, coding of a concomitant anterior approach, length of stay longer than 7 days, and bone morphogenetic protein (BMP) use. Following dichotomization, the number of revisions occurring in each subgroup at each time point was recorded. After determining which univariate variables were predictive of eventual revision, significant predictors were further analyzed with aggregate multivariate analysis.

The reason for revision or reoperation was determined by querying the number of patients who had 1 of 5 possible diagnoses entered on the same day as their revision surgery. The 5 diagnoses that were specifically queried were pseudarthrosis, instrument failure, thoracolumbar fracture, spine infection, or new neurological deficit (Table 2). New neurological deficit was queried by assessing the number of patients who had developed a neurological deficit at the time of their revision but did not have any motor or sensation deficit recorded on the day of or prior to the index procedure. The 5 diagnoses were not mutually exclusive.

\section{Statistics}

The proportion of revision surgeries in dichotomized subgroups were compared using Pearson chi-square analysis at each time point. Significant univariate predictors were further assessed by multivariate analysis to calculate the adjusted odds ratio (OR) for other significant univariate variables predictive of 5-year revision rates.

Survival analysis was then performed, with revision surgery as the primary outcome. Survivorship was defined as not having a revision surgery during the specified follow-up time. The survival function was calculated using the Kaplan-Meier method. Follow-up time was calculated by censoring patients when treated with a revision surgery or when an active record was not present. Follow-up time was estimated at 3-month intervals for the first 5 years postoperatively. Patients who were lost to follow-up between time points contributed half the interval time (e.g., 1.5 months) to follow-up.

For all analyses, $\mathrm{p}<0.005$ was considered significant because of the large cohort sizes and multiple comparisons. Statistical analyses were performed using Stata 11.0 (StataCorp LP).

\section{Results}

Of the 2293 patients included in this study, 944 (41.2\%) were $65-69$ years old, $732(31.9 \%)$ were $70-74$ years old, $457(19.9 \%)$ were $75-79$ years old, and $160(7.0 \%)$ were 80-84 years old. A total of 1810 (78.9\%) patients were female. The median Charlson Comorbidity Index score was 5 (mean $5.87 \pm 3.32$ ). Of note, $24.6 \%$ of patients had diabetes, $36.2 \%$ had COPD, $44.9 \%$ had osteoporosis, $23.0 \%$ had peripheral vascular disease, $19.9 \%$ were obese, and $34.9 \%$ had a smoking history. Concerning the surgical procedure itself, $1009(44.0 \%)$ patients had a transfusion on the same 
TABLE 1. CPT and ICD-9 codes for revision spine surgery

\begin{tabular}{lll}
\hline Category & \multicolumn{1}{c}{ ICD-9 or CPT Code } & \multicolumn{1}{c}{ Definition } \\
\hline \multirow{2}{*}{$\begin{array}{c}\text { Revision } \\
\text { surgery }\end{array}$} & P78.69 & Removal of implanted devices from bone, other bones \\
\cline { 2 - 3 } & P81.30 & Refusion of spine, not otherwise specified \\
\cline { 2 - 3 } & P81.34 & Refusion of dorsal \& dorsolumbar spine, ant column, ant technique \\
\cline { 2 - 3 } & P81.35 & Refusion of dorsal \& dorsolumbar spine, pst column, pst technique \\
\hline & P81.37 & Refusion of lumbar \& lumbosacral spine, ant column, ant technique \\
\hline P81.38 & Refusion of lumbar \& lumbosacral spine, pst column, lat transverse process technique \\
\hline P81.39 & Refusion of lumbar \& lumbosacral spine, ant column, pst technique \\
\cline { 2 - 3 } & P86.22 & Refusion of spine not elsewhere classified \\
\hline CPT-22010 & Excisional debridement of wound, infection, or burn \\
\hline CPT-22015 & Open incision \& drainage of deep abscess (subfascial), pst spine; cervical, thoracic, or cervicothoracic \\
\hline CPT-22830 & Open incision \& drainage of deep abscess (subfascial), pst spine; lumbar, sacral, or lumbosacral \\
\hline CPT-22850 & Exploration of spinal fusion \\
\hline CPT-22852 & Removal of pst nonsegmental instrumentation \\
\hline $737.1,737.10,737.19$ & Removal of pst segmental instrumentation \\
\hline $737.3,737.30,737.39$ & Kyphosis (acquired) \\
\hline $737.4,737.40,737.41,737.43$ & Kyphoscoliosis \& scoliosis \\
\hline 737.8 & Curvature of spine associated w/ other conditions \\
\hline 737.9 & Other curvatures of spine \\
\hline Deformity & Unspecified curvature of spine \\
\hline
\end{tabular}

ant $=$ anterior; pst $=$ posterior.

day, $490(21.4 \%)$ were treated with a combined anteroposterior approach, and 983 (42.9\%) were treated with BMP.

Revision rates stratified by follow-up time in the overall cohort and also by potential predictor variables are summarized in Table 3. Within 1 year of follow-up, 241 patients $(10.5 \%)$ were treated with revision surgery. This number increased to 354 (15.4\%), 394 (17.2\%), 417 (18.2\%), and $424(18.5 \%)$ within $2,3,4$, and 5 years of follow-up, respectively. When univariate statistics were considered, diabetes, obesity, smoking, and osteoporosis were found to be significant predictors of increased revisions within
1 year of follow-up. Of note, this was the only time point at which obesity was predictive. BMP use was associated with a decreased likelihood of revision surgery at 4 and 5 years of follow-up.

Multivariate adjusted ORs for each of the aforementioned univariate predictors are provided in Table 4. Significant adjusted ORs were observed with osteoporosis (OR 1.98, 95\% CI 1.60-2.46, p < 0.0001) and BMP use (OR $0.70,95 \%$ CI $0.56-0.88, p=0.002)$. Smoking history trended toward significance (OR 1.37, 95\% CI 1.10-1.70, $\mathrm{p}=0.005)$. Diabetes mellitus $(\mathrm{p}=0.013)$ and obesity $(\mathrm{p}=$

TABLE 2. Reasons for revision surgery

\begin{tabular}{|c|c|c|}
\hline Reasons For Revision & ICD-9 Code & Definition \\
\hline Pseudarthrosis & 733.82 & Nonunion of fracture (including pseudarthrosis of spine) \\
\hline Instrument failure & 996.49 & Other mechanical complication of other internal orthopedic device, implant, \& graft \\
\hline \multirow{2}{*}{$\begin{array}{l}\text { Thoracolumbar } \\
\text { fracture }\end{array}$} & $805.2,805.4,805.6,805.8$ & Closed fracture of thoracic, lumbar, sacral, coccygeal, unspecified spine w/o spinal cord injury \\
\hline & $\begin{array}{l}806.20-.29,806.4 \\
\quad 806.60-.62,806.69,806.8\end{array}$ & Closed fracture of thoracic, lumbar, sacral, coccygeal, unspecified spine w/ spinal cord injury \\
\hline \multirow[t]{6}{*}{ Neurological deficit } & 344.1 & Paraplegia \\
\hline & $344.30-.32$ & Monoplegia of lower limb \\
\hline & $344.60-.61$ & Cauda equina syndrome \\
\hline & 353.1 & Lumbosacral plexus lesions \\
\hline & 353.3 & Thoracic root lesions \\
\hline & 353.4 & Lumbosacral root lesions \\
\hline \multirow[t]{5}{*}{ Infection } & 324.1 & Intraspinal abscess \\
\hline & 998.5 & Postop infection not elsewhere classified \\
\hline & 998.51 & Infected postop seroma \\
\hline & 998.59 & Other postop infection \\
\hline & 996.67 & Infection \& inflammatory reaction due to other internal orthopedic device, implant, \& graft \\
\hline
\end{tabular}


TABLE 3. Predictors of revision rate

\begin{tabular}{|c|c|c|c|c|c|c|}
\hline Category & Total & $1 Y r$ & 2 Yrs & 3 Yrs & 4 Yrs & 5 Yrs \\
\hline No. of revision patients (\%) & 2293 & $241(10.5)$ & $354(15.4)$ & $394(17.2)$ & $417(18.2)$ & $424(18.5)$ \\
\hline \multicolumn{7}{|l|}{ Demographics } \\
\hline \multicolumn{7}{|l|}{ Age in yrs } \\
\hline$<75$ & 1676 & $196(10.8)$ & $287(15.8)$ & $318(17.6)$ & $339(18.7)$ & $345(19.1)$ \\
\hline$\geq 75$ & 617 & $45(9.3)$ & $67(13.9)$ & $76(15.7)$ & $78(16.1)$ & $79(16.4)$ \\
\hline \multicolumn{7}{|l|}{ Sex } \\
\hline $\mathrm{F}$ & 1810 & $181(10.8)$ & $266(15.9)$ & $303(18.1)$ & $323(19.3)$ & $329(19.6)$ \\
\hline M & 483 & $60(9.7)$ & $88(14.3)$ & $91(14.7)$ & $94(15.2)$ & $95(15.4)$ \\
\hline \multicolumn{7}{|l|}{ Comorbid conditions } \\
\hline \multicolumn{7}{|l|}{ Diabetes mellitus } \\
\hline No & 1728 & $163(9.4)$ & $246(14.2)$ & $270(15.6)$ & $291(16.8)$ & $296(17.1)$ \\
\hline Yes & 565 & $78(13.8)^{*}$ & $108(19.1)$ & $124(21.9)^{*}$ & $126(22.3)^{*}$ & $128(22.6)^{*}$ \\
\hline \multicolumn{7}{|l|}{ COPD } \\
\hline No & 1462 & $144(9.8)$ & $212(14.5)$ & $233(15.9)$ & $243(16.6)$ & $246(16.8)$ \\
\hline Yes & 831 & 97 (11.7) & $142(17.1)$ & $161(19.4)$ & $174(20.9)$ & $178(21.4)$ \\
\hline \multicolumn{7}{|c|}{ Peripheral vascular disease } \\
\hline No & 1765 & $177(10.0)$ & $261(14.8)$ & $286(16.2)$ & $304(17.2)$ & $308(17.4)$ \\
\hline Yes & 528 & 64 (12.1) & $93(17.6)$ & $108(20.4)$ & $113(21.4)$ & $116(22.0)$ \\
\hline \multicolumn{7}{|l|}{ Obesity } \\
\hline No & 1836 & $174(9.5)$ & $266(14.5)$ & $299(16.3)$ & $318(17.3)$ & $322(17.5)$ \\
\hline Yes & 457 & $67(14.7)^{*}$ & $88(19.2)$ & $95(20.8)$ & $99(21.7)$ & $102(22.3)$ \\
\hline \multicolumn{7}{|l|}{ Smoking history } \\
\hline No & 1492 & $135(9.0)$ & $216(14.5)$ & $232(15.5)$ & $244(16.4)$ & $248(16.6)$ \\
\hline Yes & 801 & $106(13.2)^{*}$ & $138(17.2)$ & $162(20.2)^{*}$ & $173(21.6)^{\star}$ & $176(22.0)^{*}$ \\
\hline \multicolumn{7}{|l|}{ Osteoporosis } \\
\hline No & 1263 & $110(8.7)$ & $151(12.0)$ & $167(13.2)$ & $175(13.8)$ & $178(14.1)$ \\
\hline Yes & 1030 & $131(12.7)^{*}$ & $203(19.7)^{*}$ & $227(22.0)^{*}$ & $242(23.5)^{*}$ & $246(23.9)^{*}$ \\
\hline \multicolumn{7}{|l|}{ Surgical factors } \\
\hline \multicolumn{7}{|l|}{ Same-day transfusion } \\
\hline No & 1284 & $134(10.4)$ & $204(15.9)$ & $226(17.6)$ & $242(18.8)$ & $245(19.1)$ \\
\hline Yes & 1009 & $107(10.6)$ & $150(14.9)$ & $168(16.7)$ & $175(17.3)$ & $179(17.7)$ \\
\hline \multicolumn{7}{|l|}{ Circumferential approach } \\
\hline No & 1803 & $194(10.8)$ & $291(16.1)$ & $325(18.0)$ & $343(19.0)$ & $350(19.4)$ \\
\hline Yes & 490 & $47(9.6)$ & $63(12.8)$ & 69 (14.1) & $74(15.1)$ & $74(15.1)$ \\
\hline \multicolumn{7}{|l|}{ BMP use } \\
\hline No & 1310 & $156(11.9)$ & $224(17.1)$ & $250(19.1)$ & $265(20.2)^{*}$ & $272(20.8)^{*}$ \\
\hline Yes & 983 & $85(8.6)$ & $130(13.2)$ & $144(14.6)$ & $152(15.5)$ & $152(15.5)$ \\
\hline \multicolumn{7}{|l|}{ Length of stay $>7$ days } \\
\hline No & 1427 & $145(10.2)$ & $215(15.1)$ & $233(16.3)$ & $245(17.2)$ & $252(17.6)$ \\
\hline Yes & 866 & $96(11.1)$ & $139(16.0)$ & $161(18.6)$ & $172(19.9)$ & $172(19.9)$ \\
\hline
\end{tabular}

* Significant difference between the 2 subgroups at the indicated time point $(p<0.005)$

0.038) did not prove to be significant. A survival function for the full cohort is provided in Fig. 1. Of note, at 1 year, 3 years, and 5 years following surgery, it was estimated that $87.3 \%, 73.9 \%$, and $68.8 \%$ of patients, respectively, would not have had a revision surgery.

Five specific diagnoses were separately queried in revision cases to determine the reasons for revision surgery (Fig. 2). Instrument failure was consistently the most com- monly cited reason for revision, with 129 (53.5\%) patients having undergone revision for this reason at 1 year and $264(62.3 \%)$ patients at 5 years. Infection was the next most common reason for revision surgery, with $58(24.1 \%)$ patients at 1 year and $90(21.2 \%)$ patients through 5 years.

\section{Discussion}

At 5 years of follow-up, the proportion of patients 
TABLE 4. Adjusted OR for univariate variables predictive of 5-year revision rates*

\begin{tabular}{lcccc}
\hline \multicolumn{1}{c}{ Variable } & $\begin{array}{c}\text { Adjusted } \\
\text { OR }\end{array}$ & $\begin{array}{c}95 \% \mathrm{Cl} \\
\text { Lower }\end{array}$ & $\begin{array}{c}95 \% \mathrm{Cl} \\
\text { Upper }\end{array}$ & p Value \\
\hline Diabetes mellitus & 1.36 & 1.07 & 1.73 & 0.013 \\
\hline Obesity & 1.32 & 1.01 & 1.72 & 0.038 \\
\hline Smoking history & 1.37 & 1.10 & 1.70 & 0.005 \\
\hline Osteoporosis & $\mathbf{1 . 9 8}$ & $\mathbf{1 . 6 0}$ & $\mathbf{2 . 4 6}$ & $<\mathbf{0 . 0 0 0 1}$ \\
\hline BMP use & $\mathbf{0 . 7 0}$ & $\mathbf{0 . 5 6}$ & $\mathbf{0 . 8 8}$ & $\mathbf{0 . 0 0 2}$ \\
\hline
\end{tabular}

* Boldface type indicates statistical significance.

who had undergone a revision surgery following 8-level or greater spine fusion was $18.5 \%$, up from $10.5 \%$ at the 1-year follow-up. Obesity was a significant univariate predictor of increased revisions at 1 year of follow-up, while BMP use was predictive of decreased revisions at 4 and 5 years of follow-up. Multivariate analysis revealed that when adjusting for significant univariate predictors, only osteoporosis (OR 1.98) and BMP use (OR 0.70) were significant predictors of revision, with smoking history (OR 1.37) trending toward significance. Overall, instrument failure was the most common reason for revision surgery, representing a coded diagnosis at the time of revision surgery in over $50 \%$ of cases at every follow-up time point. Five years following surgery, it was estimated that the cohort had $68.8 \%$ survivorship.

Risk factor analysis for outcomes following index spine procedures can differ greatly depending on the outcome of choice. Identifying risk factors for pseudarthrosis, implant failure, or deformity progression is distinct from categorizing predictors of eventual revision, as increasing age or comorbidities play a significant role in determining the health risks of further surgery. For example, although patients with rod fracture, a common reason for revision, tend to be older and have a higher body mass index (BMI), ${ }^{37}$ increasing age and comorbidities have been shown to be significant predictors of both increasing ${ }^{10,26,27,38}$ and decreasing risk of revision. ${ }^{12}$ Regarding age, a study by Deyo et al. found that patients who were 70 years of age or younger were almost twice as likely to have surgery as those 80 years or older (14.2\% vs $7.0 \%)$, a significant finding in a population restricted to elderly patients treated for lumbar stenosis. ${ }^{12}$ In contrast, a study by Zhu et al. found that patients aged 20-29 years and 30-39 years were significantly less likely to have a revision surgery following an index procedure for ASD than those older than 40 years. ${ }^{38}$ Furthermore, a study by Hart et al. found that age was not a significant predictor of whether a surgeon decided to perform revision surgery in patients with proximal junctional failure following ASD correction..$^{18}$ Conclusions from these 3 studies are difficult to compare since they are derived from different age groups, pathologies, and socioeconomic groups. Results in the present study agreed with the findings of Hart et al., ${ }^{18}$ which stated that age was not a significant predictor of increased risk of revision.

Comorbid conditions remain important factors to consider when predicting future risk of revision surgery. In our study, obesity was a significant predictor of revision surgery at 1 year of follow-up, but it was not significant following multivariate analysis at 5 years of follow-up perhaps because of the higher risk of infections during the early postoperative period, a risk that is known to increase with elevated BMI in patients undergoing lumbar spine surgery. ${ }^{6,10,13,19,31}$ Smoking history did approach significance on multivariate analysis $(p=0.005)$, suggesting that this comorbidity may play a role in predicting an increased risk of revision surgery. A positive smoking history has been shown to predict reoperation following both $\mathrm{ASD}^{27}$ and laminectomy ${ }^{10}$ procedures. Osteoporosis, a nontraditional comorbidity, has also been found to be a significant risk factor for eventual revision surgery, probably as a result of poor instrumentation purchase..$^{17}$

Lastly, BMP use was associated with a lower risk of revision surgery at 4 and 5 years of follow-up, a relationship that persisted following adjustment for other significant univariate predictors. Previous studies have demonstrated that BMP use decreases the risk of revision surgery following single-level lumbar fusion ${ }^{7}$ and fusions of 8 levels or greater..$^{30}$ Our finding suggests that BMP use may ensure improved outcomes in the elderly deformity population, but further studies are needed to investigate how revision risk changes with shorter fusions and how complication

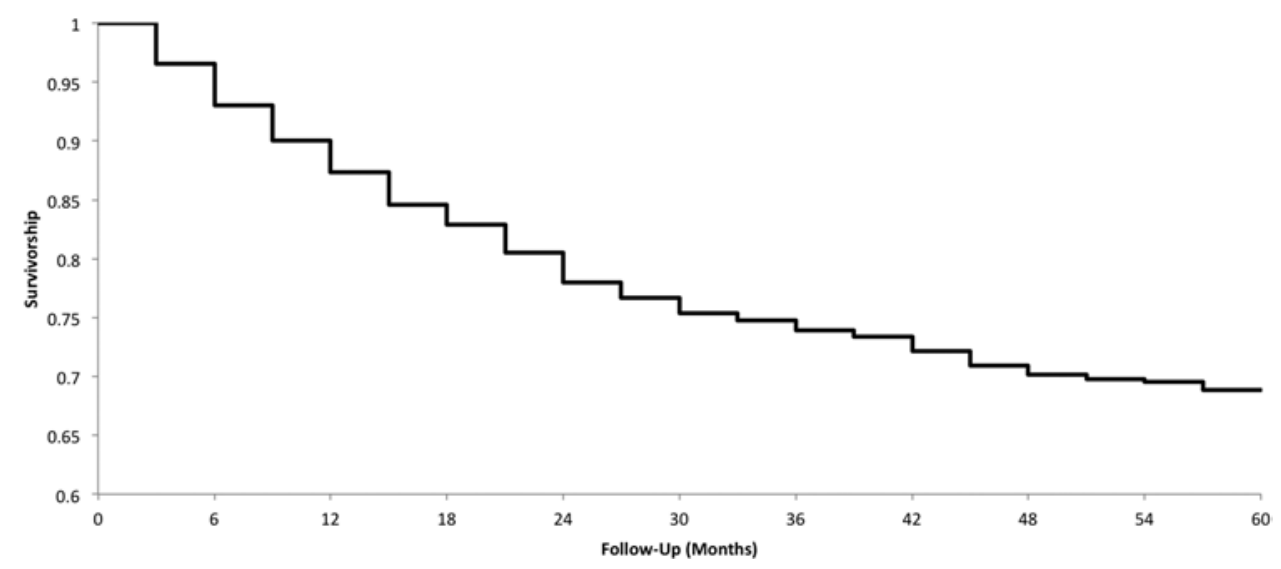

FIG. 1. Survivorship curve for all 2293 patients included in this study. 


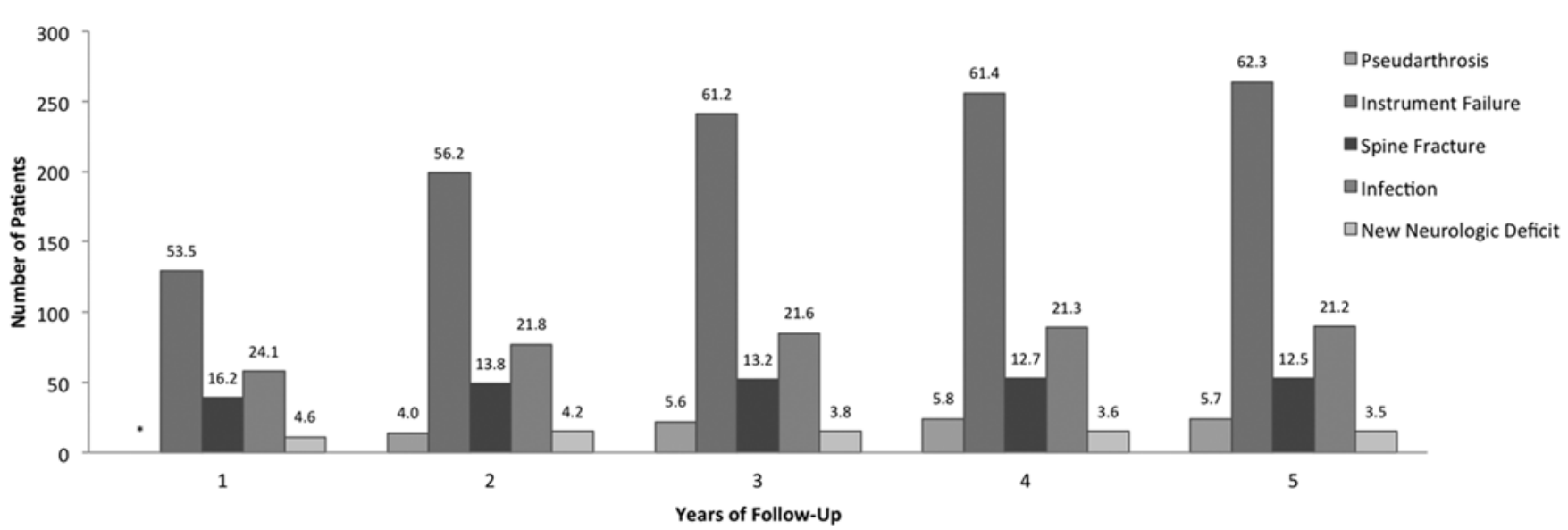

FIG. 2. Reasons for revision. For each reason, the proportion of the total number of revised patients for each year of follow-up is provided above each bar.

rates are affected by BMP use in the elderly deformity population.

Survivorship probability, as calculated by Kaplan-Meier estimates, fell within the range of previously reported values. Mok et al. estimated that survivorship without reoperation in patients with ASD was $86.4 \%$ at 1 year, $77.2 \%$ at 2 years, and $75.2 \%$ at 3 years. ${ }^{27}$ In contrast, at a mean follow-up of 4.7 years, Pichelmann et al. reported a $9.0 \%$ revision rate, ${ }^{32}$ while at a mean follow-up of 6.9 years, Zhu et al. reported a $7.6 \%$ revision rate for 5-level or greater fusions at their respective institutions. ${ }^{38}$ Notably, in our study, survivorship probabilities ranged from $87.3 \%$ at 1 year to $68.8 \%$ at 5 years.

In terms of reasons for revision surgery, our results agreed with those of previous studies. A large body of literature reveals the management of pseudarthrosis, implant failure, infection, and adjacent segment disease as an indication for reoperation following spine surgery. ${ }^{1,2,15,28,29}$ The study by Zhu et al. demonstrated that among 60 patients who had undergone revision surgery following the surgical management of ASD, implant breakage was the clear indication in $37 \%$ of the patients, while deformity progression, infection, and pseudarthrosis were the indications for further treatment in $16.1 \%, 14.5 \%$, and $12.9 \%$ of revisions, respectively. ${ }^{38}$ These results are similar to those found in the present study, as most patients had undergone revision surgery for implant failure. Unfortunately, we were unable to determine the incidence of proximal junctional kyphosis and deformity progression because of code restrictions.

The elderly population represents an important, but poorly studied, demographic. With the aid of a national database, we were able to more specifically characterize the reoperation rates observed in this patient population with an analysis of risk factors. Unfortunately, this study has several limitations, some of which are due to restrictions from using an administrative database. Firstly, our analysis is contingent upon accurately coded data. Miscoding of surgical procedures and patient characteristics is not rare ${ }^{16}$ but ideally represents only a minority of cases in our series. Furthermore, specific codes cannot capture the full extent of clinical spine surgery, limiting accurate analysis of surgery-specific factors. For example, coding for proximal junctional kyphosis and deformity progression was elusive within the ICD-9 coding system, preventing accurate determination of the relative incidence of each of these factors as a reason for revision surgery. Similarly, we were not able to assess functional outcomes and the rate at which elderly patients were offered revision surgery, facts that significantly limit interpretation of these data. Additionally, we were not able to stratify and control for an aggregate comorbidity index, a consideration that could affect risk factor assessment. Lastly, the quality of follow-up in such databases is difficult to assess. As a result, our reoperation rates probably underestimate true rates, as they are not censored for deaths.

\section{Conclusions}

Reoperation rates following posterolateral fusions of 8 levels or greater for deformity in elderly patients increased from $10.5 \%$ at 1 year of follow-up to $18.5 \%$ at 5 years of follow-up. Following multivariate analysis at 5 years of follow-up, osteoporosis (OR 1.98) and BMP use (OR 0.70) were associated with significantly increased and decreased rates of revision, respectively. Positive smoking history (OR 1.37) trended toward significance. Implant failure was the most commonly coded indication for revision surgery. It was estimated that the cohort had $68.8 \%$ survivorship 5 years following surgery.

\section{References}

1. Adogwa O, Parker SL, Shau D, Mendelhall SK, Cheng J, Aaronson O, et al: Long-term outcomes of revision fusion for lumbar pseudarthrosis: clinical article. J Neurosurg Spine 15:393-398, 2011

2. Albert TJ, Pinto M, Denis F: Management of symptomatic lumbar pseudarthrosis with anteroposterior fusion. A functional and radiographic outcome study. Spine (Phila Pa 1976) 25:123-130, 2000

3. Bridwell KH, Baldus C, Berven S, Edwards C II, Glassman $\mathrm{S}$, Hamill C, et al: Changes in radiographic and clinical outcomes with primary treatment adult spinal deformity surgeries from two years to three- to five-years follow-up. Spine (Phila Pa 1976) 35:1849-1854, 2010 
4. Bridwell KH, Glassman S, Horton W, Shaffrey C, Schwab F, Zebala LP, et al: Does treatment (nonoperative and operative) improve the two-year quality of life in patients with adult symptomatic lumbar scoliosis: a prospective multicenter evidence-based medicine study. Spine (Phila Pa 1976) 34:2171-2178, 2009

5. Brodke DS, Annis P, Lawrence BD, Woodbury AM, Daubs MD: Reoperation and revision rates of 3 surgical treatment methods for lumbar stenosis associated with degenerative scoliosis and spondylolisthesis. Spine (Phila Pa 1976) 38:2287-2294, 2013

6. Buerba RA, Fu MC, Gruskay JA, Long WD III, Grauer JN: Obese Class III patients at significantly greater risk of multiple complications after lumbar surgery: an analysis of 10,387 patients in the ACS NSQIP database. Spine J 14:2008-2018, 2014

7. Cahill KS, Chi JH, Groff MW, McGuire K, Afendulis CC, Claus EB: Outcomes for single-level lumbar fusion: the role of bone morphogenetic protein. Spine (Phila Pa 1976) 36:2354-2362, 2011

8. Cook S, Asher M, Lai SM, Shobe J: Reoperation after primary posterior instrumentation and fusion for idiopathic scoliosis. Toward defining late operative site pain of unknown cause. Spine (Phila Pa 1976) 25:463-468, 2000

9. Daubs MD, Lenke LG, Cheh G, Stobbs G, Bridwell KH: Adult spinal deformity surgery: complications and outcomes in patients over age 60. Spine (Phila Pa 1976) 32:22382244, 2007

10. De la Garza-Ramos R, Bydon M, Abt NB, Sciubba DM, Wolinsky JP, Bydon A, et al: The impact of obesity on short- and long-term outcomes after lumbar fusion. Spine (Phila Pa 1976) 40:56-61, 2015

11. Deyo RA, Cherkin DC, Loeser JD, Bigos SJ, Ciol MA: Morbidity and mortality in association with operations on the lumbar spine. The influence of age, diagnosis, and procedure. J Bone Joint Surg Am 74:536-543, 1992

12. Deyo RA, Martin BI, Kreuter W, Jarvik JG, Angier H, Mirza SK: Revision surgery following operations for lumbar stenosis. J Bone Joint Surg Am 93:1979-1986, 2011

13. Djurasovic M, Bratcher KR, Glassman SD, Dimar JR, Carreon LY: The effect of obesity on clinical outcomes after lumbar fusion. Spine (Phila Pa 1976) 33:1789-1792, 2008

14. Emami A, Deviren V, Berven S, Smith JA, Hu SS, Bradford DS: Outcome and complications of long fusions to the sacrum in adult spine deformity: Luque-Galveston, combined iliac and sacral screws, and sacral fixation. Spine (Phila Pa 1976) 27:776-786, 2002

15. Ghiselli G, Wang JC, Bhatia NN, Hsu WK, Dawson EG: Adjacent segment degeneration in the lumbar spine. J Bone Joint Surg Am 86-A:1497-1503, 2004

16. Gologorsky Y, Knightly JJ, Lu Y, Chi JH, Groff MW: Improving discharge data fidelity for use in large administrative databases. Neurosurg Focus 36(6):E2, 2014

17. Halvorson TL, Kelley LA, Thomas KA, Whitecloud TS III, Cook SD: Effects of bone mineral density on pedicle screw fixation. Spine (Phila Pa 1976) 19:2415-2420, 1994

18. Hart R, McCarthy I, O’Brien M, Bess S, Line B, Adjei OB, et al: Identification of decision criteria for revision surgery among patients with proximal junctional failure after surgical treatment of spinal deformity. Spine (Phila Pa 1976) 38:E1223-E1227, 2013

19. Higgins DM, Mallory GW, Planchard RF, Puffer RC, Ali M, Gates MJ, et al: Understanding the impact of obesity on short-term outcomes and in-hospital costs after instrumented spinal fusion. Neurosurgery 78:127-132, 2016

20. Kim YJ, Bridwell KH, Lenke LG, Cho KJ, Edwards CC II, Rinella AS: Pseudarthrosis in adult spinal deformity following multisegmental instrumentation and arthrodesis. J Bone Joint Surg Am 88:721-728, 2006
21. Kim YJ, Bridwell KH, Lenke LG, Rhim S, Cheh G: Pseudarthrosis in long adult spinal deformity instrumentation and fusion to the sacrum: prevalence and risk factor analysis of 144 cases. Spine (Phila Pa 1976) 31:2329-2336, 2006

22. Lapp MA, Bridwell KH, Lenke LG, Daniel Riew K, Linville DA, Eck KR, et al: Long-term complications in adult spinal deformity patients having combined surgery a comparison of primary to revision patients. Spine (Phila Pa 1976) 26:973983, 2001

23. Lehmann TR, Spratt KF, Tozzi JE, Weinstein JN, Reinarz SJ, el-Khoury GY, et al: Long-term follow-up of lower lumbar fusion patients. Spine (Phila Pa 1976) 12:97-104, 1987

24. Li S, Zhang J, Li J, Lin J, Tian Y, Weng X, et al: Wound infection after scoliosis surgery: an analysis of 15 cases. Chin Med Sci J 17:193-198, 2002

25. Maier S, Smith JS, Schwab F, Obeid I, Mundis G, Klineberg E, et al: Revision surgery after three-column osteotomy in 335 adult spinal deformity patients: inter-center variability and risk factors. Spine (Phila Pa 1976) [epub ahead of print], 2014

26. Mesfin A, El Dafrawy MH, Jain A, Hassanzadeh H, Kostuik JP, Lemma MA, et al: Surgical outcomes of long spinal fusions for scoliosis in adult patients with rheumatoid arthritis. J Neurosurg Spine 22:367-373, 2015

27. Mok JM, Cloyd JM, Bradford DS, Hu SS, Deviren V, Smith JA, et al: Reoperation after primary fusion for adult spinal deformity: rate, reason, and timing. Spine (Phila Pa 1976) 34:832-839, 2009

28. Mok JM, Guillaume TJ, Talu U, Berven SH, Deviren V, Kroeber M, et al: Clinical outcome of deep wound infection after instrumented posterior spinal fusion: a matched cohort analysis. Spine (Phila Pa 1976) 34:578-583, 2009

29. Pateder DB, Park YS, Kebaish KM, Cascio BM, Buchowski JM, Song EW, et al: Spinal fusion after revision surgery for pseudarthrosis in adult scoliosis. Spine (Phila Pa 1976) 31:E314-E319, 2006

30. Paul JC, Lonner BS, Vira S, Kaye ID, Errico TJ: Use of recombinant bone morphogenetic protein is associated with reduced risk of reoperation after spine fusion for adult spinal deformity. Spine (Phila Pa 1976) 41:E15-E21, 2015

31. Pereira BJ, de Holanda CV, Ribeiro CA, de Moura SM, Galvão PE, Quidute BS, et al: Impact of body mass index in spinal surgery for degenerative lumbar spine disease. Clin Neurol Neurosurg 127:112-115, 2014

32. Pichelmann MA, Lenke LG, Bridwell KH, Good CR, O'Leary PT, Sides BA: Revision rates following primary adult spinal deformity surgery: six hundred forty-three consecutive patients followed-up to twenty-two years postoperative. Spine (Phila Pa 1976) 35:219-226, 2010

33. Rinella A, Bridwell K, Kim Y, Rudzki J, Edwards C, Roh M, et al: Late complications of adult idiopathic scoliosis primary fusions to L4 and above: the effect of age and distal fusion level. Spine (Phila Pa 1976) 29:318-325, 2004

34. Smith JS, Shaffrey CI, Berven S, Glassman S, Hamill C, Horton W, et al: Operative versus nonoperative treatment of leg pain in adults with scoliosis: a retrospective review of a prospective multicenter database with two-year follow-up. Spine (Phila Pa 1976) 34:1693-1698, 2009

35. Smith JS, Shaffrey CI, Glassman SD, Berven SH, Schwab FJ, Hamill CL, et al: Risk-benefit assessment of surgery for adult scoliosis: an analysis based on patient age. Spine (Phila Pa 1976) 36:817-824, 2011

36. Smith JS, Shaffrey CI, Lafage V, Schwab F, Scheer JK, Protopsaltis T, et al: Comparison of best versus worst clinical outcomes for adult spinal deformity surgery: a retrospective review of a prospectively collected, multicenter database with 2-year follow-up. J Neurosurg Spine 23:349-359, 2015

37. Smith JS, Shaffrey E, Klineberg E, Shaffrey CI, Lafage V, Schwab FJ, et al: Prospective multicenter assessment of risk 
factors for rod fracture following surgery for adult spinal deformity. J Neurosurg Spine 21:994-1003, 2014

38. Zhu F, Bao H, Liu Z, Bentley M, Zhu Z, Ding Y, et al: Unanticipated revision surgery in adult spinal deformity: an experience with 815 cases at one institution. Spine (Phila Pa 1976) 39:B36-B44, 2014

\section{Disclosures}

Dr. Shen reports being a consultant for Globus Medical, DePuy Synthes, Medtronic, and Elsevier; receiving study-related support from the AO Foundation; and serving on the MTF Medical Board of Directors, the Axsome Therapeutic Advisory Board, and the executive boards of NASS and CSRS. Dr. Shimer reports serving as a consultant for Nuvasive and Medtronic and as a speaker for Biomet.

\section{Author Contributions}

Conception and design: Puvanesarajah, Shen. Acquisition of data: Puvanesarajah. Analysis and interpretation of data: Puvanesarajah. Drafting the article: Hassanzadeh, Puvanesarajah, Shen. Critically revising the article: all authors. Reviewed submitted version of manuscript: all authors. Approved the final version of the manuscript on behalf of all authors: Hassanzadeh. Statistical analysis: Puvanesarajah, Novicoff.

\section{Supplemental Information}

Online-Only Content

Supplemental material is available with the online version of the article.

Appendix Table 1. http://thejns.org/doi/suppl/10.3171/2016.2. SPINE151345.

\section{Correspondence}

Hamid Hassanzadeh, Department of Orthopaedic Surgery, University of Virginia, Box 800159, Charlottesville, VA 22908. email: hh4xd@hscmail.mcc.virginia.edu. 